\title{
Demographics, perceptions, and socioeconomic factors affecting influenza vaccination among adults in the United States
}

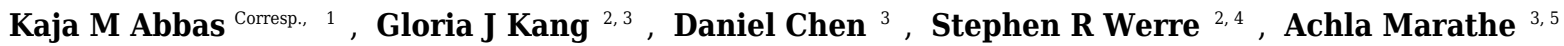 \\ 1 Department of Infectious Disease Epidemiology, London School of Hygiene \& Tropical Medicine, United Kingdom \\ 3 Biocomplexity Institute, Virginia Polytechnic Institute and State University (Virginia Tech), United States \\ 4 Laboratory for Study Design and Statistical Analysis, Virginia Polytechnic Institute and State University (Virginia Tech), United States \\ 5 Department of Agricultural and Applied Economics, Virginia Polytechnic Institute and State University (Virginia Tech), United States \\ Corresponding Author: Kaja M Abbas \\ Email address: kaja.abbas@Ishtm.ac.uk
}

Objective: The study objective is to analyze influenza vaccination status by demographic factors, perceived vaccine efficacy, social influence, herd immunity, vaccine cost, health insurance status, and barriers to influenza vaccination among adults 18 years and older in the United States.

Background: Influenza vaccination coverage among adults 18 years and older was $41 \%$ during 20102011 and has increased and plateaued at 43\% during 2016-2017. This is below the target of 70\% influenza vaccination coverage among adults, which is an objective of the Healthy People 2020 initiative.

Methods: We conducted a survey of a nationally representative sample of adults 18 years and older in the United States on factors affecting influenza vaccination. We conducted bivariate analysis using RaoScott chi-square test and multivariate analysis using weighted multinomial logistic regression of this survey data to determine the effect of demographics, perceived vaccine efficacy, social influence, herd immunity, vaccine cost, health insurance, and barriers associated with influenza vaccination uptake among adults in the United States.

Results: Influenza vaccination rates are relatively high among adults in older age groups (73.3\% among $75+$ year old), adults with education levels of bachelor's degree or higher (45.1\%), non-Hispanic Whites $(41.8 \%)$, adults with higher incomes (52.8\% among adults with income of over $\$ 150,000)$, partnered adults (43.2\%), non-working adults (46.2\%), and adults with internet access (39.9\%). Influenza vaccine is taken every year by $76 \%$ of adults who perceive that the vaccine is very effective, $64.2 \%$ of adults who are socially influenced by others, and $41.8 \%$ of adults with health insurance, while $72.3 \%$ of adults without health insurance never get vaccinated. Facilitators for adults getting vaccinated every year in comparison to only some years include older age, perception of high vaccine effectiveness, higher income and no out-of-pocket payments. Barriers for adults never getting vaccinated in comparison to only some years include lack of health insurance, disliking of shots, perception of low vaccine effectiveness, low perception of risk for influenza infection, and perception of risky side effects.

Conclusion: Influenza vaccination rates among adults in the United States can be improved towards the Healthy People 2020 target of $70 \%$ by increasing awareness of the safety, efficacy and need for influenza vaccination, leveraging the practices and principles of commercial and social marketing to improve vaccine trust, confidence and acceptance, and lowering out-of-pocket expenses and covering influenza vaccination costs through health insurance. 
3 Kaja M. Abbas ${ }^{1}$, Gloria J. Kang ${ }^{2,3}$, Daniel Chen ${ }^{3}$, Stephen R. Werre ${ }^{2,4}$, Achla Marathe $e^{3,5}$

4 1Department of Infectious Disease Epidemiology, London School of Hygiene \& Tropical

5 Medicine, United Kingdom

$6 \quad{ }^{2}$ Department of Population Health Sciences, Virginia Polytechnic Institute and State University

7 (Virginia Tech), United States

8 3Biocomplexity Institute, Virginia Polytechnic Institute and State University (Virginia Tech),

9 United States

$10{ }^{4}$ Laboratory for Study Design and Statistical Analysis, Virginia Polytechnic Institute and State

11 University (Virginia Tech), United States

$12{ }^{5}$ Department of Agricultural and Applied Economics, Virginia Polytechnic Institute and State

13 University (Virginia Tech), United States 


\section{ABSTRACT}

Objective: The study objective is to analyze influenza vaccination status by demographic factors, perceived vaccine efficacy, social influence, herd immunity, vaccine cost, health insurance status, and barriers to influenza vaccination among adults 18 years and older in the United States.

Background: Influenza vaccination coverage among adults 18 years and older was $41 \%$ during 2010-2011 and has increased and plateaued at 43\% during 2016-2017. This is below the target of $70 \%$ influenza vaccination coverage among adults, which is an objective of the Healthy People 2020 initiative.

Methods: We conducted a survey of a nationally representative sample of adults 18 years and older in the United States on factors affecting influenza vaccination. We conducted bivariate analysis using Rao-Scott chi-square test and multivariate analysis using weighted multinomial logistic regression of this survey data to determine the effect of demographics, perceived vaccine efficacy, social influence, herd immunity, vaccine cost, health insurance, and barriers associated with influenza vaccination uptake among adults in the United States.

Results: Influenza vaccination rates are relatively high among adults in older age groups (73.3\% among $75+$ year old), adults with education levels of bachelor's degree or higher (45.1\%), non-Hispanic Whites (41.8\%), adults with higher incomes (52.8\% among adults with income of over $\$ 150,000)$, partnered adults (43.2\%), non-working adults $(46.2 \%)$, and adults with internet access (39.9\%). Influenza vaccine is taken every year by $76 \%$ of adults who perceive that the vaccine is very effective, $64.2 \%$ of adults who are socially influenced by others, and $41.8 \%$ of adults with health insurance, while $72.3 \%$ of adults without health insurance never get vaccinated. Facilitators for adults getting vaccinated every year in comparison to only some years include older age, perception of high vaccine effectiveness, higher income and no out-of-pocket payments. Barriers for adults never getting vaccinated in comparison to only some years include lack of health insurance, disliking of shots, perception of 
46 low vaccine effectiveness, low perception of risk for influenza infection, and perception of risky

47 side effects.

48 Conclusion: Influenza vaccination rates among adults in the United States can be improved

49 towards the Healthy People 2020 target of $70 \%$ by increasing awareness of the safety, efficacy

50 and need for influenza vaccination, leveraging the practices and principles of commercial and

51 social marketing to improve vaccine trust, confidence and acceptance, and lowering out-of-

52 pocket payments and covering influenza vaccination costs through health insurance.

53

54

55 


\section{INTRODUCTION}

57 Influenza has caused between 9.2 million and 35.6 million illnesses, between 140,000 and

58710,000 hospitalizations, and between 12,000 and 56,000 deaths annually in the United States

59 since 2010.(CDC) Influenza vaccination is an effective public health intervention to lower the

60 morbidity and mortality burden from influenza. The Advisory Committee on Immunization

61 Practices of the Centers for Disease Control and Prevention recommends influenza vaccination

62 for everyone 6 months or older.(Grohskopf et al., 2017) Influenza vaccination coverage among

63 children (6 months to 17 years) was $59.0 \%$ and among adults (18 years and older) was $43.3 \%$

64 during the 2016-2017 influenza season.(CDC) While the influenza vaccination coverage among

65 adults 18 years and older has increased from 40.5\% during 2010-2011 to 43.3\% during 2016-

662017 , it has plateaued and is below the target of $70 \%$ influenza vaccination coverage among

67 adults as part of the Healthy People 2020 initiative.(Healthy People 2020)

68

69 Knowledge, attitudes, and beliefs affecting influenza vaccination

70 Prior studies have identified demographic factors, and knowledge, attitudes and beliefs affecting

71 influenza vaccination, especially among elderly Americans. Demographic factors include

72 age(van Essen, Kuyvenhoven \& de Melker, 1997; Petersen et al., 1999) and race.(CDC)

73 Facilitators include the awareness of the safety, efficacy and need for influenza

74 vaccination,(Centers for Disease Control and Prevention (CDC), 1999) physician

75 recommendations,(Centers for Disease Control and Prevention (CDC), 1999; Zimmerman et al., 76 2003) fear of contracting influenza without influenza vaccination,(Zimmerman et al., 2003) social

77 forces influencing vaccination behavior,(Tabbarah et al., 2005) and disagreement with the view

78 that the vaccine is detrimental,(Tabbarah et al., 2005) while barriers include fear of side

79 effects,(Centers for Disease Control and Prevention (CDC), 1999) efficacy concerns,(Fiebach \&

80 Viscoli, 1991; Centers for Disease Control and Prevention (CDC), 1999) and fear of vaccines 
81 causing influenza.(Nichol, Lofgren \& Gapinski, 1992; Centers for Disease Control and

82 Prevention (CDC), 1999; Zimmerman et al., 2003)

83 


\section{Study objective}

85 The study objective is to analyze influenza vaccination status by demographic factors, perceived

86 vaccine efficacy, social influence, herd immunity, vaccine cost, health insurance status, and

87 barriers to influenza vaccination among adults 18 years and older in the United States.

88

89 Public health significance

90 The public health significance of this study is to understand and analyze the demographics,

91 perceptions, and socioeconomic factors affecting influenza vaccination among adults in the

92 United States, and provide evidence to improve influenza vaccination rates among the adults

93 toward the Healthy People 2020 target of $70 \%$.(Healthy People 2020)

94

95

96

97

98 
99

100

101

102

103

104

105

106

107

108

109

110

111

112

113

114

115

116

117

118

119

120

\section{Bivariate analysis}

122 We analyzed vaccination status by respondent's gender, age, education, ethnicity, income, 123

124

\section{METHODS}

We conducted an online survey in 2016 of a nationally representative sample of the general population of adults 18 years and over in the United States. Data was collected from 2,150 respondents in the survey which was administered by the Gfk Group using a sample from KnowledgePanel, a probabilistic-based web panel designed to be representative of the United States population. The Institutional Review Board at Virginia Tech granted ethical approval for this study (IRB \# 14-712), and the survey was conducted by the Gfk Group with the consent of the participants.

\section{Survey questionnaire}

Survey questions were based on the health behavioral framework of the health belief model(Rosenstock, 1974; Coe et al., 2012; Santos et al., 2017) and the socioecological model.(McLeroy et al., 1988; Kumar et al., 2012; Niyibizi, Schamel \& Frew, 2016) The health belief model illustrates that health-related behavior, such as getting influenza vaccine, is influenced by perceived susceptibility, perceived severity, perceived benefits, perceived barriers, cues to action, and self-efficacy. The socioecological model explains that health-related behavior of individuals is influenced by their perceptions, social influences, and structural factors such as access to health care and insurance. Specifically, our survey questions were focused on understanding perceived vaccine efficacy, social influences and herd immunity, vaccine cost and health insurance, and barriers affecting influenza vaccination in adults, as illustrated in Table 1. marital status, metro status, region, work status, and internet access using Rao-Scott's chisquare test (Table 2). We also analyzed vaccination status by perceived vaccine efficacy, social 
125 influence and herd immunity, vaccine cost and health insurance, and barriers to vaccination 126 using Rao-Scott's chi-square test (Table 3).

127 Marital status refers to partnered adults (married or living together) and single adults 128 (never married, separated, divorced, or widowed). Metro status refers to metropolitan areas with 129 a relatively high population density at its centre with proximal economic ties throughout the area. 130 Working status refers to working as a paid employee and working as self-employed; categories 131 of non-working status includes temporary layoff, looking for work, retired, disabled, and other.

132 Region refers to Midwest, Northeast, South, and West regions of the US. Internet access refers 133 to access to the internet and is not specific to access at work or home nor is based on the 134 usage.

\section{Multivariate analysis}

137 Statistically significant variables ( $p$-value $\leq 0.05)$ from the bivariate analysis were included in the forward selection procedure for multivariate analysis using weighted multinomial logistic regression. We analyzed respondent demographics (age, education, income, region, work status), perceived efficacy, social influence, cost and health insurance associated with getting the influenza vaccine using weighted multinomial logistic regression (Table 4). We compared

142 the responses of adults who get the influenza vaccine every year to those who get the influenza vaccine some years. We analyzed demographics (age, education, income, region, work status), perceived efficacy, health insurance, and barriers associated with not getting the influenza vaccine using weighted multinomial logistic regression (Table 5). We compared the responses of adults who never get the influenza vaccine to those who get the influenza vaccine some

147 years. All statistical analysis was performed using the R software for statistical computing.("R:

148 The R Project for Statistical Computing") 
150

151

152

153

154

155

156

157

158

159

160

161

162

163

164

165

166

167

168

169

170

171

172

173 Influenza vaccination by perceived efficacy, social influence, herd immunity, vaccine

174

\section{RESULTS}

\section{Influenza vaccination by demographics}

We analyzed influenza vaccination status of adults by gender, age, education, ethnicity, income, marital status, metro status, region, work status, and internet access using Rao-Scott's chisquare test, as illustrated in Table 2. Vaccination status refers to adults being vaccinated every year, some years, or never with the influenza vaccine. We observed an association between vaccination status and the demographic variables of age, education, ethnicity, income, marital status, work status, and internet access.

$73.3 \%$ of adults over 75 get vaccinated every year compared to only $25.5 \%$ of $18-24$ year old adults. $45.1 \%$ of adults with a bachelor's degree or higher get vaccinated every year compared with $34.7 \%$ of adults with less than a high school education. $41.8 \%$ of White, nonHispanic adults get vaccinated every year, while $53.7 \%$ of non-Hispanic $2+$ races' adults and $48.2 \%$ of non-Hispanic Black adults never get vaccinated. $52.8 \%$ of adults earning more than $\$ 150,000$ get vaccinated every year compared with $27.2 \%$ of adults earning less than $\$ 10,000$. $43.2 \%$ of partnered adults get vaccinated every year while $46.4 \%$ of single adults never get vaccinated. $46.2 \%$ of non-working adults get vaccinated every year compared with $34.1 \%$ of the working adults. $39.9 \%$ of adults with internet access get vaccinated every year compared with $35.9 \%$ of adults without internet access.

Similar proportions of adults get vaccinated every year in both metro $(38.9 \%)$ and nonmetro $(39.9 \%)$ areas. Regional vaccination status rates were also similar, with a relatively higher proportion of adults $(40.3 \%)$ in the Northeast getting vaccinated every year compared with the lowest proportion of $37.2 \%$ in the American West. cost, health insurance, and barriers 
175 We performed bivariate analysis using Rao-Scott's chi-square test to analyze influenza

176 vaccination status by perceived efficacy, social influence, herd immunity, vaccine cost, health

177 insurance, and barriers to vaccination, and observed an association between them as illustrated

178 in Table 3.

$17976 \%$ of adults who perceive that the vaccine is very effective get vaccinated every year 180 compared with $31.2 \%$ who perceive that the vaccine is not effective. $64.2 \%$ of adults, who are

181 more likely to get influenza vaccination if others around them are also vaccinated, get

182 vaccinated every year. $78.4 \%$ of adults, who are more likely to get vaccinated if others around

183 them do not get vaccinated, get vaccinated every year. $68.3 \%$ of adults, who get influenza

184 vaccination to protect themselves and others, also get vaccinated every year.

$41.8 \%$ of adults with health insurance get vaccinated every year compared with $11.3 \%$ of adults without health insurance, while $72.3 \%$ of adults without health insurance never get vaccinated. $71.9 \%$ of adults who have null out-of-pocket payment for the influenza vaccine get vaccinated every year compared to $46.5 \%$ of those who pay $\$ 30$ to $\$ 60$. Similarly, $54.5 \%$ of adults who have the vaccine cost fully covered by their health insurance get vaccinated every year compared with $36.3 \%$ of adults who do not have the benefit. $46 \%$ of adults who are impacted by high vaccine cost never get vaccinated. $56.6 \%$ of adults who perceive that the vaccine is not very effective in preventing influenza, $74.8 \%$ of adults who perceive that they are unlikely to get influenza, and $77.9 \%$ of adults who perceive that the vaccine side effects are too risky never get vaccinated. $73.8 \%$ of adults who do not like shots and $52 \%$ of adults who just do not get around to getting vaccinated, never get vaccinated.

197 Demographics, perceived efficacy, social influence, herd immunity, vaccine cost, and 198 health insurance associated with getting influenza vaccination

199 We analyzed demographics (age, education, income, region, work status), perceived efficacy, 200 social influence, herd immunity, vaccine cost, and health insurance associated with getting 
201 influenza vaccine using weighted multinomial logistic regression, as illustrated in Table 4. The

202 responses by the adults for getting influenza vaccination every year are compared to the 203 responses by the adults for getting influenza vaccination some years.

204 The odds of getting vaccinated every year (versus some years) were significantly higher 205 for adults 55 years and older compared to younger adults 18-24 years, with an adjusted odds 206 ratio (AOR) of 9.87 for adults 75 years and older, 4.46 for adults $65-74$ years, and 3.43 for 207 adults 55-64 years. Adults with annual income exceeding $\$ 150,000$ had significantly higher 208 odds $(A O R=3.59)$ of getting vaccinated every year (versus some years) compared to those 209 with incomes below $\$ 10,000$.

210 Adults who perceive that the influenza vaccine is not effective are $84 \%$ less likely (AOR

$211=0.16$ ) to get vaccinated every year (versus some years) compared to adults who perceive that 212 it is very effective. Adults who were less likely to get vaccinated if others around them did not 213 get vaccinated were $78 \%$ less likely $(A O R=0.22)$ to get vaccinated every year (versus some 214 years), compared to the adults who were more likely to get vaccinated if others around them did 215 not get vaccinated. Adults who get the influenza vaccine to protect others were $62 \%$ less likely $216($ AOR $=0.38)$ to get vaccinated every year (versus some years), compared to the adults who 217 get vaccinated to protect themselves. The odds of getting vaccinated every year (versus some 218 years) were significantly lower for adults with out-of-pocket payments for the influenza vaccine 219 compared to the adults with no out-of-pocket payments, with an adjusted odds ratio of 0.42 220 (58\% less likely) and 0.39 (61\% less likely) for adults with out-of-pocket payment of less than $221 \$ 30$ and $\$ 30-\$ 60$ respectively.

222

223 Demographics, perceived efficacy, health insurance, and barriers associated with not 224 getting influenza vaccination

225 We analyzed demographics (age, education, income, region, work status), perceived efficacy, 226 health insurance, and barriers associated with not getting influenza vaccine using weighted 
227 multinomial logistic regression, as illustrated in Table 5. The responses by the adults for never 228 getting influenza vaccination are compared to the responses by the adults for getting influenza 229 vaccination some years.

230 Adults who perceive that the influenza vaccine is not effective are more likely $(A O R=$ 10.36) to never getting vaccinated (versus getting vaccinated some years) compared to adults who perceive that it is very effective. Adults without health insurance are more likely (AOR = 2.04) to never getting vaccinated (versus getting vaccinated some years) compared to adults with health insurance. to never get vaccinated (versus getting vaccinated some years). Adults who perceived that the vaccine side effects are too risky are $98 \%$ more likely $(A O R=1.98)$ to never get vaccinated (versus getting vaccinated some years). Adults who do not like shots are $48 \%$ more likely (AOR $=1.48)$ to never get vaccinated (versus getting vaccinated some years). get vaccinated (versus getting vaccinated some years). Adults who perceive that the vaccine is not very effective in preventing influenza are $59 \%$ less likely $(A O R=0.41)$ to never get vaccinated (versus getting vaccinated some years). Adults who just do not get around to getting vaccinated are $48 \%$ less likely $(A O R=0.52)$ to never get vaccinated (versus getting vaccinated some years). While high cost, perception of low vaccine efficacy, and not getting around to getting vaccinated are barriers associated with never getting vaccinated, adults with these barriers are still more likely to get vaccinated some years compared to never getting vaccinated. 


\section{DISCUSSION}

\section{Demographics}

254 The proportion of adults getting influenza vaccination every year increases with age, while the 255 proportion of adults never getting influenza vaccination decreases with age. Adults with higher 256 education levels (bachelor's degree or higher) are more likely to get vaccinated every year, 257 while the proportion of adults who never get vaccinated increases with low education levels.

258 While a high proportion of non-Hispanic White adults get vaccinated every year, a large 259 proportion of non-Hispanic Black adults never get vaccinated. Adults with higher income are 260 more likely to get vaccinated every year, while the proportion of adults who never get vaccinated 261 increases with lower income. Partnered adults (married, living together) are more likely to get vaccinated every year, while single adults (never married, divorced, widowed) are more likely to never get vaccinated. Adults living in non-metro areas are more likely to never get vaccinated similar to adults without internet access, while adults with internet access are more likely to get vaccinated every year.

266

\section{Perceptions and socioeconomic factors}

Adults who perceive that the influenza vaccine is very effective are more likely to get vaccinated every year, while adults who perceive that the influenza vaccine is not effective are more likely to never get vaccinated. A higher proportion of adults are getting vaccinated every year to

271 protect themselves and others, and they are influenced by vaccine uptake behavior within their

272 social networks. Adults with health insurance are more likely to get vaccinated every year, while 273 adults without health insurance are more likely to never get vaccinated. Adults without out-of274 pocket payments, as well as those for whom the cost of influenza vaccination is fully covered by 275 health insurance, are more likely to get vaccinated every year. Adults who do not get vaccinated 276 every year are more likely to never get vaccinated due to low perceptions of vaccine 
277 effectiveness and risk of influenza infection, high perception of risky side effects, disliking shots, 278 and "just not getting around to do it".

279

280 Facilitators

281 Facilitators for adults getting vaccinated every year in comparison to only some years include 282 older age, perception of high vaccine effectiveness, higher income and no out-of-pocket 283 payments. Elderly adults are likely to get the influenza vaccine every year based on their 284 positive experience of influenza vaccination from past years, as well as act on the influenza 285 vaccine recommendation of their physicians during their clinical visits on health conditions that 286 are not necessarily related to influenza.(Lu et al., 2016) Adults with a perception of high vaccine 287 effectiveness are likely to get the influenza vaccination based on their positive vaccine 288 sentiment. Higher income and no out-of-pocket payments through health insurance minimize the financial burden of the influenza vaccine cost as well as the cost of taking time off from work and travel to get the vaccine.(Jerant et al., 2013)

Adults are also influenced by vaccine uptake behavior within their social networks, 292 including a higher likelihood of adults getting vaccinated every year if others around them are not vaccinated. This social influence can be partly explained by the Philipson model(Geoffard \& Philipson, 1997; Philipson, 2000) which posits that higher disease prevalence leads to higher demand for public health interventions. An individual within a network of unvaccinated people has an enhanced risk of infection for influenza, thereby nudging the individual's choice to protect themselves by getting vaccinated.

\section{Barriers}

300 Barriers for adults never getting vaccinated in comparison to only some years include lack of 301 health insurance, disliking of shots, perception of low vaccine effectiveness, low perception of 302 risk for influenza infection, and perception of risky side effects. Adults without health insurance 
303 are less likely to seek preventive care including influenza vaccination.(Jerant et al., 2013) While

304 the live attenuated influenza vaccine administered through a intranasal sprayer may appeal to

305 adults who dislike shots in comparison to the inactivated influenza vaccine administered through

306 an intramuscular injection, the Advisory Committee on Immunization Practices does not

307 recommend the use of live attenuated influenza vaccine.(Grohskopf et al., 2017)

308 Vaccine hesitancy and negative vaccine sentiment continues to contribute to suboptimal

309 vaccination coverage in the United States for influenza and other vaccine-preventable diseases, 310 posing significant risk of disease outbreaks.(Kang, Culp \& Abbas, 2017; Kang et al., 2017) The

311 perception of negative sentiment in vaccine effectiveness, risk for influenza infection and risky

312 side effects lends to vaccine hesitancy and reduces trust and confidence in influenza vaccines.

313 Vaccine hesitancy can be addressed by leveraging the commercial and social marketing

314 practices and principles of the four P's, namely Product, Price, Place and Promotion.(Nowak et

315 al., 2015) Specific to influenza vaccination, the product is the influenza vaccine, recommended

316 annual vaccination schedule of individuals 6 months and older, and the act of getting

317 vaccinated. The price category refers to the cost, convenience, ease of access, and perception

318 of safety and efficacy of the influenza vaccine. The place category refers to the location where

319 the influenza vaccine is administered, such as doctors' offices, clinics, and pharmacies. The

320 promotion category refers to the influenza vaccine messaging and communication through

321 posters, brochures, public service advertisements and websites, outreach through traditional

322 news media and social media, spokespersons, and interpersonal communication including

323 patient-provider communication. Thereby, addressing vaccine hesitancy and improving trust and

324 confidence in vaccines by leveraging these principles and practices in commercial and social

325 marketing has appreciable value in improving influenza vaccine acceptance.(Larson et al.,

326 2015, 2018; Nowak et al., 2015)

327

328 Limitations 
329 Our survey was administered to a nationally representative sample of adults 18 years and older 330 in the United States; thereby, we are unable to extend our analysis to include children below 18 331 years of age.

332

333 


\section{CONCLUSION}

335 Health program strategies based on systems thinking focus on an ongoing, iterative learning of 336 systems understanding, analysis, and improvement.(Swanson et al., 2012) Influenza

337 vaccination rates among adults in the United States are impacted by demographics, 338 perceptions, and socioeconomic factors. Through systematic understanding, analysis, and 339 identification of these influencing factors, this study provides evidence to improve the design

340 and implementation of current and future influenza vaccination programs by leveraging the

341 facilitators and addressing the barriers. Specifically, the public health implications of this study

342 are that the influenza vaccination rates among adults in the United States can be improved

343 towards the Healthy People 2020 target of $70 \%$ by increasing awareness of the safety, efficacy

344 and need for influenza vaccination, leveraging the practices and principles of commercial and 345 social marketing to improve vaccine trust, confidence and acceptance, and lowering out-of346 pocket payments and covering influenza vaccination costs through health insurance. 


\section{REFERENCES}

349 CDC. Disease Burden of Influenza.

350 CDC. Flu Vaccination Coverage, United States, 2016-17 Influenza Season. FluVaxView.

351 Centers for Disease Control and Prevention (CDC). 1999. Reasons reported by Medicare

352 beneficiaries for not receiving influenza and pneumococcal vaccinations--United States,

353 1996. MMWR. Morbidity and Mortality Weekly Report 48:886-890.

354 Coe AB., Gatewood SBS., Moczygemba LR., Goode J-VKR., Beckner JO. 2012. The use of the

355 health belief model to assess predictors of intent to receive the novel (2009) H1N1

356 influenza vaccine. Innovations in pharmacy 3:1-11.

357 van Essen GA., Kuyvenhoven MM., de Melker RA. 1997. Why do healthy elderly people fail to

358 comply with influenza vaccination? Age and Ageing 26:275-279.

359 Fiebach NH., Viscoli CM. 1991. Patient acceptance of influenza vaccination. The American

$360 \quad$ Journal of Medicine 91:393-400.

361 Geoffard P-Y., Philipson T. 1997. Disease Eradication: Private versus Public Vaccination. The

$362 \quad$ American Economic Review 87:222-230.

363 Grohskopf LA., Sokolow LZ., Broder KR., Walter EB., Bresee JS., Fry AM., Jernigan DB. 2017.

364 Prevention and Control of Seasonal Influenza with Vaccines: Recommendations of the 365 Advisory Committee on Immunization Practices - United States, 2017-18 Influenza Season.

366 MMWR. Recommendations and Reports: Morbidity and Mortality Weekly Report 66:1-20.

367 Healthy People 2020. Immunization and Infectious Diseases | Healthy People 2020. Healthy

$368 \quad$ People 2020.

369 Jerant A., Fiscella K., Tancredi DJ., Franks P. 2013. Health insurance is associated with

370 preventive care but not personal health behaviors. Journal of the American Board of Family

$371 \quad$ Medicine 26:759-767.

372 Kang GJ., Culp RK., Abbas KM. 2017. Facilitators and barriers of parental attitudes and beliefs 373 toward school-located influenza vaccination in the United States: Systematic review. 
Vaccine 35:1987-1995.

375 Kang GJ., Ewing-Nelson SR., Mackey L., Schlitt JT., Marathe A., Abbas KM., Swarup S. 2017. 376 Semantic network analysis of vaccine sentiment in online social media. Vaccine 35:3621$377 \quad 3638$.

378 Kumar S., Quinn SC., Kim KH., Musa D., Hilyard KM., Freimuth VS. 2012. The social ecological 379 model as a framework for determinants of $2009 \mathrm{H} 1 \mathrm{~N} 1$ influenza vaccine uptake in the 380 United States. Health education \& behavior: the official publication of the Society for Public $381 \quad$ Health Education 39:229-243.

382 Larson HJ., Clarke RM., Jarrett C., Eckersberger E., Levine Z., Schulz WS., Paterson P. 2018. 383 Measuring trust in vaccination: A systematic review. Human vaccines \& 384 immunotherapeutics:1-11.

385 Larson HJ., Schulz WS., Tucker JD., Smith DMD. 2015. Measuring vaccine confidence: 386 introducing a global vaccine confidence index. PLoS Currents. Influenza 7.

387 Lu P-J., O’Halloran A., Ding H., Srivastav A., Williams WW. 2016. Uptake of Influenza 388 Vaccination and Missed Opportunities Among Adults with High-Risk Conditions, United 389 States, 2013. The American Journal of Medicine 129:636.e1-636.e11.

390 McLeroy KR., Bibeau D., Steckler A., Glanz K. 1988. An ecological perspective on health $391 \quad$ promotion programs. Health education quarterly 15:351-377.

392 Nichol KL., Lofgren RP., Gapinski J. 1992. Influenza vaccination. Knowledge, attitudes, and 393 behavior among high-risk outpatients. Archives of Internal Medicine 152:106-110.

394 Niyibizi N., Schamel J., Frew PM. 2016. Neighborhood Influences on Seasonal Influenza 395 Vaccination among Older African Americans in Atlanta, Georgia. Journal of immunological $396 \quad$ techniques in infectious diseases 5.

397 Nowak GJ., Gellin BG., MacDonald NE., Butler R., SAGE Working Group on Vaccine Hesitancy. 398 2015. Addressing vaccine hesitancy: The potential value of commercial and social 399 marketing principles and practices. Vaccine 33:4204-4211. 
400 Petersen RL., Saag K., Wallace RB., Doebbeling BN. 1999. Influenza and pneumococcal 401 vaccine receipt in older persons with chronic disease: a population-based study. Medical 402 Care 37:502-509.

403 Philipson T. 2000. Chapter 33 Economic epidemiology and infectious diseases. In: Handbook of $404 \quad$ health economics. Elsevier, 1761-1799.

405 R: The R Project for Statistical Computing

406 Rosenstock IM. 1974. Historical Origins of the Health Belief Model. Health education \& 407 behavior: the official publication of the Society for Public Health Education 2:328-335.

408 Santos AJ., Kislaya I., Machado A., Nunes B. 2017. Beliefs and attitudes towards the influenza $409 \quad$ vaccine in high-risk individuals. Epidemiology and Infection 145:1786-1796.

410 Swanson RC., Cattaneo A., Bradley E., Chunharas S., Atun R., Abbas KM., Katsaliaki K., 411 Mustafee N., Mason Meier B., Best A. 2012. Rethinking health systems strengthening: key 412 systems thinking tools and strategies for transformational change. Health Policy and $413 \quad$ Planning 27 Suppl 4:iv54-61.

414 Tabbarah M., Zimmerman RK., Nowalk MP., Janosky JE., Troy JA., Raymund M., Jewell IK. 415 2005. What predicts influenza vaccination status in older Americans over several years? $416 \quad$ Journal of the American Geriatrics Society 53:1354-1359.

417 Zimmerman RK., Santibanez TA., Janosky JE., Fine MJ., Raymund M., Wilson SA., Bardella IJ., 418 Medsger AR., Nowalk MP. 2003. What affects influenza vaccination rates among older 419 patients? An analysis from inner-city, suburban, rural, and Veterans Affairs practices. The $420 \quad$ American Journal of Medicine 114:31-38. 


\section{Table $\mathbf{1}$ (on next page)}

Influenza vaccination survey.

Factors of vaccination status, perceived efficacy, social influence, herd immunity, vaccine cost, health insurance, and barriers to vaccination were included in the survey questionnaire. 
1 Table 1: Influenza vaccination survey. Factors of vaccination status, perceived efficacy,

2 social influence, herd immunity, vaccine cost, health insurance, and barriers to vaccination were

3 included in the survey questionnaire.

\begin{tabular}{|c|c|c|}
\hline Factors & Survey questions & Response choices \\
\hline Vaccination status & Do you get an influenza vaccine? & $\begin{array}{l}\text { 1. Yes, every year } \\
\text { 2. Yes, some years } \\
\text { 3. No, never }\end{array}$ \\
\hline Perceived efficacy & $\begin{array}{l}\text { How effective do you think the influenza } \\
\text { vaccine is in protecting people from } \\
\text { becoming sick with influenza? }\end{array}$ & $\begin{array}{l}\text { 1. Very effective } \\
\text { 2. Somewhat effective } \\
\text { 3. Not effective } \\
\text { 4. It varies from season to } \\
\text { season } \\
\text { 5. Don't know }\end{array}$ \\
\hline \multirow[t]{2}{*}{ Social influence } & $\begin{array}{l}\text { Are you more likely to get a vaccine if } \\
\text { others around you get a vaccine? }\end{array}$ & $\begin{array}{l}\text { 1. Yes, more likely } \\
\text { 2. No, less likely } \\
\text { 3. No, no effect }\end{array}$ \\
\hline & $\begin{array}{l}\text { Are you more likely to get a vaccine if } \\
\text { others around you do not get a } \\
\text { vaccine? }\end{array}$ & $\begin{array}{l}\text { 1. Yes, more likely } \\
\text { 2. No, less likely } \\
\text { 3. No, no effect }\end{array}$ \\
\hline Herd immunity & $\begin{array}{l}\text { Do you get a vaccine to protect } \\
\text { yourself, protect others, or protect } \\
\text { yourself and others? }\end{array}$ & $\begin{array}{l}\text { 1. Protect myself } \\
\text { 2. Protect others } \\
\text { 3. Protect myself and others }\end{array}$ \\
\hline Vaccine cost & $\begin{array}{l}\text { How much do you pay to get an } \\
\text { influenza vaccine? }\end{array}$ & $\begin{array}{l}\text { 1. } \$ 0 \\
\text { 2. Less than } \$ 30 \\
\text { 3. } \$ 30 \text { to } \$ 60 \\
\text { 4. More than } 60 \$ \\
\text { 5. Don't know }\end{array}$ \\
\hline \multirow[t]{2}{*}{ Health insurance } & Do you have health insurance? & $\begin{array}{l}\text { 1. Yes } \\
\text { 2. No }\end{array}$ \\
\hline & $\begin{array}{l}\text { Are influenza vaccines covered by your } \\
\text { health insurance? }\end{array}$ & $\begin{array}{l}\text { 1. Yes, the full cost is paid } \\
\text { 2. Yes, but only part of the } \\
\text { cost is paid } \\
\text { 3. No } \\
\text { 4. Don't know }\end{array}$ \\
\hline Barriers & $\begin{array}{l}\text { What are the reasons you would not get } \\
\text { an influenza vaccine? } \\
\text { (check all that apply) }\end{array}$ & $\begin{array}{l}\text { 1. The vaccine costs too } \\
\text { much } \\
\text { 2. The vaccine is not very } \\
\text { effective in preventing }\end{array}$ \\
\hline
\end{tabular}




\begin{tabular}{|l|l|}
\hline & $\begin{array}{l}\text { influenza } \\
\text { 3. I am not likely to get } \\
\text { influenza }\end{array}$ \\
4. Do not know where to get \\
vaccine \\
5. The side effects of the \\
vaccine are too risky \\
6. I am allergic to some of \\
the ingredients in the \\
vaccine \\
7. I do not like shots \\
8. I just don't get around to \\
doing it \\
9. I have to travel too far to \\
get vaccine \\
10. Other, please specify
\end{tabular}

4

5

6

7

8 


\section{Table 2 (on next page)}

Demographic characteristics of survey respondents.

Respondent characteristics by gender, age, education, ethnicity, income, marital status, metro status, region, work status, and internet access among adults 18 years and older in the United States. 
1 Table 2: Demographic characteristics of survey respondents. Respondent characteristics

2 by gender, age, education, ethnicity, income, marital status, metro status, region, work status,

3 and internet access among adults 18 years and older in the United States.

\begin{tabular}{|c|c|c|c|c|c|c|c|c|}
\hline & & \multicolumn{7}{|c|}{ Do you get an influenza vaccine? $(n=2150)$} \\
\hline & & \multicolumn{2}{|c|}{$\begin{array}{l}\text { Yes, every year } \\
(n=908)\end{array}$} & \multicolumn{2}{|c|}{$\begin{array}{c}\text { Yes, some years } \\
(n=423)\end{array}$} & \multicolumn{2}{|c|}{ No, never $(n=819)$} & \multirow[t]{2}{*}{$p$-value } \\
\hline \multicolumn{2}{|c|}{ Respondent characteristics } & $\mathrm{n}$ & $\%$ & $\mathrm{n}$ & $\%$ & $\mathrm{n}$ & $\%$ & \\
\hline \multirow[t]{3}{*}{ Gender } & & & & & & & & \\
\hline & Female & 460 & $39.4 \%$ & 227 & $21.8 \%$ & 408 & $38.8 \%$ & 0.4 \\
\hline & Male & 448 & $38.6 \%$ & 196 & $19.8 \%$ & 411 & $41.6 \%$ & \\
\hline \multicolumn{9}{|c|}{ Age (years) } \\
\hline & $18-24$ & 45 & $25.5 \%$ & 49 & $29.2 \%$ & 78 & $45.3 \%$ & $<0.001$ \\
\hline & $25-34$ & 73 & $24.0 \%$ & 82 & $28.4 \%$ & 134 & $47.6 \%$ & \\
\hline & $35-44$ & 102 & $30.9 \%$ & 75 & $23.2 \%$ & 147 & $45.9 \%$ & \\
\hline & $45-54$ & 138 & $35.5 \%$ & 86 & $22.8 \%$ & 160 & $41.7 \%$ & \\
\hline & $55-64$ & 238 & $47.8 \%$ & 78 & $14.6 \%$ & 181 & $37.6 \%$ & \\
\hline & $65-74$ & 201 & $58.3 \%$ & 45 & $13.6 \%$ & 93 & $28.1 \%$ & \\
\hline & $75+$ & 111 & $73.3 \%$ & 8 & $6.2 \%$ & 26 & $20.5 \%$ & \\
\hline \multicolumn{9}{|c|}{ Education level } \\
\hline & $\begin{array}{l}\text { Less than high } \\
\text { school }\end{array}$ & 60 & $34.7 \%$ & 27 & $17.6 \%$ & 73 & $47.7 \%$ & $<0.001$ \\
\hline & High school & 271 & $40.9 \%$ & 79 & $13.6 \%$ & 279 & $45.5 \%$ & \\
\hline & Some college & 218 & $32.3 \%$ & 147 & $26.6 \%$ & 239 & $41.1 \%$ & \\
\hline & $\begin{array}{l}\text { Bachelor's degree } \\
\text { or higher }\end{array}$ & 359 & $45.1 \%$ & 170 & $24.0 \%$ & 228 & $30.9 \%$ & \\
\hline \multicolumn{9}{|c|}{ Ethnicity } \\
\hline & $\begin{array}{l}\text { White, Non- } \\
\text { Hispanic }\end{array}$ & 696 & $41.8 \%$ & 293 & $19.8 \%$ & 567 & $38.5 \%$ & 0.01 \\
\hline & $\begin{array}{l}\text { Black, Non- } \\
\text { Hispanic }\end{array}$ & 69 & $33.2 \%$ & 37 & $18.6 \%$ & 88 & $48.2 \%$ & \\
\hline & Hispanic & 80 & $32.8 \%$ & 54 & $24.5 \%$ & 94 & $42.8 \%$ & \\
\hline & $\begin{array}{l}\text { Other, Non- } \\
\text { Hispanic }\end{array}$ & 36 & $37.9 \%$ & 28 & $28.3 \%$ & 29 & $33.8 \%$ & \\
\hline & $\begin{array}{l}\text { 2+ Races, Non- } \\
\text { Hispanic }\end{array}$ & 27 & $31.5 \%$ & 11 & $14.8 \%$ & 41 & $53.7 \%$ & \\
\hline \multicolumn{9}{|l|}{ Income } \\
\hline & under $\$ 10 \mathrm{k}$ & 24 & $27.2 \%$ & 15 & $17.0 \%$ & 50 & $55.8 \%$ & $<0.001$ \\
\hline & $\$ 10 k$ to $\$ 25 k$ & 83 & $30.7 \%$ & 36 & $16.7 \%$ & 118 & $52.6 \%$ & \\
\hline & $\$ 25 \mathrm{k}$ to $\$ 50 \mathrm{k}$ & 178 & $37.6 \%$ & 81 & $19.2 \%$ & 183 & $43.2 \%$ & \\
\hline & $\$ 50 \mathrm{k}$ to $\$ 75 \mathrm{k}$ & 168 & $37.9 \%$ & 78 & $21.8 \%$ & 158 & $40.3 \%$ & \\
\hline
\end{tabular}




\begin{tabular}{|c|c|c|c|c|c|c|c|c|}
\hline & $\$ 75 k$ to $\$ 100 k$ & 131 & $37.9 \%$ & 74 & $24.3 \%$ & 106 & $37.9 \%$ & \\
\hline & $\$ 100 k$ to $\$ 150 k$ & 213 & $44.3 \%$ & 99 & $23.3 \%$ & 146 & $32.4 \%$ & \\
\hline & over $\$ 150 \mathrm{k}$ & 111 & $52.8 \%$ & 40 & $19.8 \%$ & 58 & $27.3 \%$ & \\
\hline \multicolumn{9}{|l|}{ Marital Status } \\
\hline & Single & 302 & $33.7 \%$ & 160 & $19.9 \%$ & 374 & $46.4 \%$ & $<0.001$ \\
\hline & Partnered & 606 & $43.2 \%$ & 263 & $21.6 \%$ & 445 & $35.3 \%$ & \\
\hline \multicolumn{9}{|l|}{ Metro Status } \\
\hline & Metro & 772 & $38.9 \%$ & 376 & $21.9 \%$ & 682 & $39.2 \%$ & 0.02 \\
\hline & Non-metro & 136 & $39.9 \%$ & 47 & $14.9 \%$ & 137 & $45.2 \%$ & \\
\hline \multicolumn{9}{|l|}{ Region } \\
\hline & Midwest & 203 & $39.0 \%$ & 91 & $19.9 \%$ & 182 & $41.1 \%$ & 0.002 \\
\hline & Northeast & 174 & $40.3 \%$ & 81 & $19.8 \%$ & 164 & $39.9 \%$ & \\
\hline & South & 330 & $39.5 \%$ & 127 & $17.4 \%$ & 303 & $43.1 \%$ & \\
\hline & West & 201 & $37.2 \%$ & 124 & $28.1 \%$ & 170 & $34.6 \%$ & \\
\hline \multicolumn{9}{|l|}{ Work status } \\
\hline & Not working & 454 & $46.2 \%$ & 142 & $17.5 \%$ & 296 & $36.2 \%$ & $<0.001$ \\
\hline & Working & 454 & $34.1 \%$ & 281 & $23.1 \%$ & 523 & $42.8 \%$ & \\
\hline \multicolumn{9}{|l|}{ Internet status } \\
\hline & No & 130 & $35.9 \%$ & 49 & $15.1 \%$ & 172 & $49.0 \%$ & $<0.001$ \\
\hline & Yes & 778 & $39.9 \%$ & 374 & $22.4 \%$ & 647 & $37.7 \%$ & \\
\hline
\end{tabular}




\section{Table 3(on next page)}

Perceived efficacy, social influence, herd immunity, vaccine cost, health insurance, and barriers.

Perceived efficacy, social influence, herd immunity, vaccine cost, health insurance, and barriers by vaccination status among adults 18 years and older in the United States. 
1 Table 3: Perceived efficacy, social influence, herd immunity, vaccine cost, health

2 insurance, and barriers. Perceived efficacy, social influence, herd immunity, vaccine cost,

3 health insurance, and barriers by vaccination status among adults 18 years and older in the

4 United States.

\begin{tabular}{|c|c|c|c|c|c|c|c|c|c|}
\hline \multirow[b]{3}{*}{ Variable } & \multirow[b]{3}{*}{ Response } & \multicolumn{7}{|c|}{ Do you get an influenza vaccine? } & \multirow[b]{3}{*}{$\begin{array}{c}\text { Total } \\
(n=2150)\end{array}$} \\
\hline & & \multicolumn{2}{|c|}{$\begin{array}{l}\text { Yes, every year } \\
(n=908)\end{array}$} & \multicolumn{2}{|c|}{$\begin{array}{l}\text { Yes, some years } \\
(n=423)\end{array}$} & \multicolumn{2}{|c|}{$\begin{array}{l}\text { No, never } \\
(\mathrm{n}=819)\end{array}$} & \multirow[b]{2}{*}{$p$-value } & \\
\hline & & $\mathrm{n}$ & $\%$ & $\mathrm{n}$ & $\%$ & $\mathrm{n}$ & $\%$ & & \\
\hline \multicolumn{10}{|l|}{ Perceived efficacy } \\
\hline \multirow{5}{*}{$\begin{array}{l}\text { How effective do } \\
\text { you think the } \\
\text { influenza vaccine } \\
\text { is in protecting } \\
\text { people from } \\
\text { becoming sick } \\
\text { with influenza? }\end{array}$} & Very effective & 304 & $76.0 \%$ & 45 & $14.1 \%$ & 34 & $9.9 \%$ & $<0.001$ & 383 \\
\hline & Somewhat effective & 435 & $41.6 \%$ & 240 & $26.9 \%$ & 285 & $31.5 \%$ & & 960 \\
\hline & Not effective & 141 & $31.2 \%$ & 94 & $21.8 \%$ & 198 & $47.0 \%$ & & 433 \\
\hline & $\begin{array}{l}\text { It varies from } \\
\text { season to season }\end{array}$ & 6 & $4.4 \%$ & 16 & $14.2 \%$ & 120 & $81.4 \%$ & & 142 \\
\hline & Don't know & 19 & $7.8 \%$ & 27 & $12.5 \%$ & 180 & $79.7 \%$ & & 226 \\
\hline \multicolumn{10}{|l|}{ Social influence } \\
\hline \multirow{3}{*}{$\begin{array}{l}\text { Are you more } \\
\text { likely to get a } \\
\text { vaccine if others } \\
\text { around you get a } \\
\text { vaccine? }\end{array}$} & Yes, more likely & 254 & $64.2 \%$ & 127 & $35.8 \%$ & - & - & $<0.001$ & 381 \\
\hline & No, no effect & 620 & $68.1 \%$ & 258 & $31.9 \%$ & - & - & & 878 \\
\hline & No, less likely & 33 & $43.1 \%$ & 37 & $57.0 \%$ & - & - & & 70 \\
\hline \multirow{3}{*}{$\begin{array}{l}\text { Are you more } \\
\text { likely to get a } \\
\text { vaccine if others } \\
\text { around you do not } \\
\text { get a vaccine? }\end{array}$} & Yes, more likely & 252 & $78.4 \%$ & 61 & $21.6 \%$ & - & - & $<0.001$ & 313 \\
\hline & No, no effect & 610 & $64.6 \%$ & 294 & $35.4 \%$ & - & - & & 904 \\
\hline & No, less likely & 37 & $33.6 \%$ & 64 & $66.4 \%$ & - & - & & 101 \\
\hline \multicolumn{10}{|l|}{ Herd immunity } \\
\hline \multirow{3}{*}{$\begin{array}{l}\text { Do you get a } \\
\text { vaccine to protect } \\
\text { yourself, protect } \\
\text { others, or protect } \\
\text { yourself and } \\
\text { others? }\end{array}$} & Protect myself & 243 & $60.2 \%$ & 138 & $39.8 \%$ & - & - & $<0.001$ & 381 \\
\hline & $\begin{array}{l}\text { Protect myself and } \\
\text { others }\end{array}$ & 653 & $68.3 \%$ & 268 & $31.8 \%$ & - & - & & 921 \\
\hline & Protect others & 6 & $26.2 \%$ & 16 & $73.8 \%$ & - & - & & 22 \\
\hline \multicolumn{10}{|l|}{ Vaccine cost } \\
\hline \multirow{3}{*}{$\begin{array}{l}\text { How much do you } \\
\text { pay to get an } \\
\text { influenza } \\
\text { vaccine? }\end{array}$} & $\$ 0$ & 723 & $71.9 \%$ & 247 & $28.1 \%$ & - & - & $<0.001$ & 970 \\
\hline & Less than $\$ 20$ & 118 & $51.7 \%$ & 104 & $48.3 \%$ & - & - & & 222 \\
\hline & $\$ 30$ to $\$ 60$ & 28 & $46.5 \%$ & 26 & $53.5 \%$ & - & - & & 54 \\
\hline
\end{tabular}




\begin{tabular}{|c|c|c|c|c|c|c|c|c|c|}
\hline & More than $\$ 60$ & - & - & - & - & - & - & & - \\
\hline & Don't know & 34 & $35.8 \%$ & 46 & $64.2 \%$ & - & - & & 80 \\
\hline \multicolumn{10}{|l|}{ Health insurance } \\
\hline \multirow{2}{*}{$\begin{array}{l}\text { Do you have } \\
\text { health insurance? }\end{array}$} & Yes & 887 & $41.8 \%$ & 396 & $21.2 \%$ & 708 & $37.0 \%$ & $<0.001$ & 1991 \\
\hline & No & 19 & $11.3 \%$ & 24 & $16.4 \%$ & 110 & $72.3 \%$ & & 153 \\
\hline \multirow{4}{*}{$\begin{array}{l}\text { Are influenza } \\
\text { vaccines covered } \\
\text { by your health } \\
\text { insurance? }\end{array}$} & $\begin{array}{l}\text { Yes, the full cost is } \\
\text { paid }\end{array}$ & 731 & $54.5 \%$ & 249 & $20.7 \%$ & 301 & $24.8 \%$ & $<0.001$ & 1281 \\
\hline & Yes, but only part & 61 & $36.3 \%$ & 47 & $34.6 \%$ & 44 & $29.2 \%$ & & 152 \\
\hline & No & 19 & $36.3 \%$ & 13 & $23.6 \%$ & 23 & $40.1 \%$ & & 55 \\
\hline & Don't know & 75 & $14.6 \%$ & 86 & $18.2 \%$ & 339 & $67.2 \%$ & & 500 \\
\hline \multicolumn{10}{|l|}{ Barriers } \\
\hline \multirow{9}{*}{$\begin{array}{l}\text { What are the } \\
\text { reasons you } \\
\text { would not get an } \\
\text { influenza } \\
\text { vaccine? }\end{array}$} & $\begin{array}{l}\text { 1. The vaccine } \\
\text { costs too much }\end{array}$ & - & - & 61 & $54.0 \%$ & 49 & $46.0 \%$ & $<0.001$ & 110 \\
\hline & $\begin{array}{l}\text { 2. The vaccine is } \\
\text { not very effective in } \\
\text { preventing } \\
\text { influenza }\end{array}$ & - & - & 143 & $43.4 \%$ & 196 & $56.6 \%$ & $<0.001$ & 339 \\
\hline & $\begin{array}{l}\text { 3. I am not likely to } \\
\text { get influenza }\end{array}$ & - & - & 75 & $25.2 \%$ & 203 & $74.8 \%$ & $<0.001$ & 278 \\
\hline & $\begin{array}{l}\text { 4. Do not know } \\
\text { where to get the } \\
\text { vaccine }\end{array}$ & - & - & 14 & $35.4 \%$ & 19 & $62.6 \%$ & 0.9 & 33 \\
\hline & $\begin{array}{l}\text { 5. The side effects } \\
\text { of the vaccine are } \\
\text { too risky }\end{array}$ & - & - & 65 & $22.2 \%$ & 219 & $77.9 \%$ & $<0.001$ & 284 \\
\hline & $\begin{array}{l}\text { 6. I am allergic to } \\
\text { some of the } \\
\text { ingredients in the } \\
\text { vaccine }\end{array}$ & - & - & 23 & $40.4 \%$ & 35 & $59.6 \%$ & 0.3 & 58 \\
\hline & $\begin{array}{l}\text { 7. I do not like } \\
\text { shots }\end{array}$ & - & - & 70 & $26.2 \%$ & 196 & $73.8 \%$ & 0.004 & 266 \\
\hline & $\begin{array}{l}8.1 \text { just don't get } \\
\text { around to doing it }\end{array}$ & - & - & 183 & $48.0 \%$ & 181 & $52.0 \%$ & $<0.001$ & 364 \\
\hline & $\begin{array}{l}\text { 9. I have to travel } \\
\text { too far to get } \\
\text { vaccine }\end{array}$ & - & - & 10 & $43.3 \%$ & 16 & $56.7 \%$ & 0.3 & 26 \\
\hline
\end{tabular}




\section{Table 4 (on next page)}

Demographics, perceived efficacy, social influence, herd immunity, vaccine cost and health insurance associated with getting influenza vaccine.

Demographics (age, education, income, region, work status), perceived efficacy, social influence, herd immunity, vaccine cost and health insurance associated with getting influenza vaccine among adults 18 years and older in the United States. 
1 Table 4: Demographics, perceived efficacy, social influence, herd immunity, vaccine cost

2 and health insurance associated with getting influenza vaccine. Demographics (age,

3 education, income, region, work status), perceived efficacy, social influence, herd immunity,

4 vaccine cost and health insurance associated with getting influenza vaccine among adults 18

5 years and older in the United States.

\begin{tabular}{|c|c|c|c|c|}
\hline \multicolumn{2}{|c|}{ Variable } & \multicolumn{3}{|c|}{$\begin{array}{c}\text { "Yes, every year" } \\
\text { (versus "Yes, some years") }\end{array}$} \\
\hline & & AOR & $\mathrm{Cl}$ & $p$-value \\
\hline \multirow[t]{7}{*}{ Age (years) } & (Referent: 18-24) & & & \\
\hline & $25-34$ & 1.05 & $(0.54,2.05)$ & 0.89 \\
\hline & $35-44$ & 1.47 & $(0.78,2.77)$ & 0.23 \\
\hline & $45-54$ & 1.63 & $(0.89,2.99)$ & 0.11 \\
\hline & $55-64$ & 3.43 & $(1.9,6.22)$ & $<0.001$ \\
\hline & $65-74$ & 4.46 & $(2.3,8.65)$ & $<0.001$ \\
\hline & $75+$ & 9.87 & $(3.96,24.6)$ & $<0.001$ \\
\hline \multirow[t]{4}{*}{ Education level } & $\begin{array}{l}\text { (Referent: Less than high } \\
\text { school) }\end{array}$ & & & \\
\hline & High school & 1.39 & $(0.7,2.76)$ & 0.35 \\
\hline & Some college & 0.64 & $(0.33,1.24)$ & 0.18 \\
\hline & $\begin{array}{l}\text { Bachelor's degree or } \\
\text { higher }\end{array}$ & 1.07 & $(0.54,2.09)$ & 0.85 \\
\hline \multirow[t]{7}{*}{ Income } & (Referent: Under \$10k) & & & \\
\hline & $\$ 10 k$ to $\$ 25 k$ & 1.84 & $(0.6,5.66)$ & 0.29 \\
\hline & $\$ 25 \mathrm{k}$ to $\$ 50 \mathrm{k}$ & 2.22 & $(0.74,6.6)$ & 0.15 \\
\hline & $\$ 50 \mathrm{k}$ to $\$ 75 \mathrm{k}$ & 2.65 & $(0.89,7.9)$ & 0.08 \\
\hline & $\$ 75 k$ to $\$ 100 k$ & 2.28 & $(0.76,6.88)$ & 0.14 \\
\hline & $\$ 100 k$ to $\$ 150 k$ & 2.37 & $(0.8,7.04)$ & 0.12 \\
\hline & Over $\$ 150 \mathrm{k}$ & 3.59 & $(1.16,11.04)$ & 0.03 \\
\hline \multirow[t]{4}{*}{ Region } & (Referent: Midwest) & & & \\
\hline & Northeast & 0.94 & $(0.59,1.49)$ & 0.80 \\
\hline & South & 1.10 & $(0.73,1.64)$ & 0.65 \\
\hline & West & 0.75 & $(0.49,1.15)$ & 0.19 \\
\hline \multirow[t]{2}{*}{ Work status } & (Referent: Not working) & & & \\
\hline & Working & 0.83 & $(0.59,1.16)$ & 0.27 \\
\hline
\end{tabular}




\begin{tabular}{|c|c|c|c|c|}
\hline Perceived efficacy & (Referent: Very effective) & & & \\
\hline \multirow{4}{*}{$\begin{array}{l}\text { How effective do you think } \\
\text { the influenza vaccine is in } \\
\text { protecting people from } \\
\text { becoming sick with } \\
\text { influenza? }\end{array}$} & Somewhat effective & 0.28 & $(0.19,0.42)$ & $<0.001$ \\
\hline & $\begin{array}{l}\text { It varies from season to } \\
\text { season }\end{array}$ & 0.26 & $(0.16,0.42)$ & $<0.001$ \\
\hline & Not effective & 0.16 & $(0.04,0.6)$ & 0.006 \\
\hline & Don't know & 0.15 & $(0.06,0.35)$ & $<0.001$ \\
\hline Social influence & $\begin{array}{l}\text { (Referent: Yes, more } \\
\text { likely) }\end{array}$ & & & \\
\hline \multirow{2}{*}{$\begin{array}{l}\text { Are you more likely to get a } \\
\text { vaccine if others around } \\
\text { you do not get a vaccine? }\end{array}$} & No, no effect & 0.53 & $(0.37,0.77)$ & 0.001 \\
\hline & No, less likely & 0.22 & $(0.12,0.41)$ & $<0.001$ \\
\hline Herd immunity & (Referent: Protect myself) & & & \\
\hline \multirow{2}{*}{$\begin{array}{l}\text { Do you get a vaccine to } \\
\text { protect yourself, protect } \\
\text { others, or protect yourself } \\
\text { and others? }\end{array}$} & Protect myself and others & 1.26 & $(0.92,1.72)$ & 0.14 \\
\hline & Protect others & 0.38 & $(0.14,0.99)$ & 0.05 \\
\hline Vaccine cost & (Referent: \$0) & & & \\
\hline \multirow{3}{*}{$\begin{array}{l}\text { How much do you pay to } \\
\text { get an influenza vaccine? }\end{array}$} & Less than $\$ 30$ & 0.42 & $(0.29,0.6)$ & $<0.001$ \\
\hline & $\$ 30$ to $\$ 60$ & 0.39 & $(0.2,0.77)$ & 0.007 \\
\hline & Don't know & 0.25 & $(0.13,0.46)$ & $<0.001$ \\
\hline Health insurance & (Referent: Yes) & & & \\
\hline $\begin{array}{l}\text { Do you have health } \\
\text { insurance? }\end{array}$ & No & 0.71 & $(0.32,1.6)$ & 0.41 \\
\hline
\end{tabular}




\section{Table 5 (on next page)}

Demographics, perceived efficacy, health insurance, and barriers associated with not getting influenza vaccine.

Demographics (age, education, income, region, work status), perceived efficacy, health insurance, and barriers associated with not getting influenza vaccine among adults 18 years and older in the United States. 
1 Table 5: Demographics, perceived efficacy, health insurance, and barriers associated

2 with not getting influenza vaccine. Demographics (age, education, income, region, work

3 status), perceived efficacy, health insurance, and barriers associated with not getting influenza

4 vaccine among adults 18 years and older in the United States.

\begin{tabular}{|c|c|c|c|c|}
\hline & \multirow[t]{2}{*}{ Variable } & \multicolumn{3}{|c|}{$\begin{array}{c}\text { "No, never" } \\
\text { (versus "Yes, some years") }\end{array}$} \\
\hline & & AOR & $\mathrm{Cl}$ & $\mathrm{p}$-value \\
\hline \multirow[t]{7}{*}{ Age (years) } & (Referent: 18-24) & & & \\
\hline & $25-34$ & 0.92 & $(0.53,1.62)$ & 0.78 \\
\hline & $35-44$ & 1.20 & $(0.70,2.04)$ & 0.51 \\
\hline & $45-54$ & 1.09 & $(0.66,1.79)$ & 0.74 \\
\hline & $55-64$ & 1.40 & $(0.84,2.35)$ & 0.20 \\
\hline & $65-74$ & 1.04 & $(0.57,1.90)$ & 0.91 \\
\hline & $75+$ & 1.62 & $(0.60,4.34)$ & 0.34 \\
\hline \multirow[t]{4}{*}{ Education level } & (Referent: Less than high school) & & & \\
\hline & High school & 1.69 & $(0.92,3.08)$ & 0.09 \\
\hline & Some college & 0.64 & $(0.35,1.17)$ & 0.15 \\
\hline & Bachelor's degree or higher & 0.69 & $(0.38,1.28)$ & 0.24 \\
\hline \multirow[t]{7}{*}{ Income } & (Referent: Under \$10k) & & & \\
\hline & $\$ 10 k$ to $\$ 25 k$ & 1.24 & $(0.53,2.90)$ & 0.61 \\
\hline & $\$ 25 \mathrm{k}$ to $\$ 50 \mathrm{k}$ & 0.91 & $(0.43,1.91)$ & 0.80 \\
\hline & $\$ 50 \mathrm{k}$ to $\$ 75 \mathrm{k}$ & 0.90 & $(0.41,1.98)$ & 0.80 \\
\hline & $\$ 75 k$ to $\$ 100 k$ & 0.75 & $(0.34,1.65)$ & 0.48 \\
\hline & $\$ 100 \mathrm{k}$ to $\$ 150 \mathrm{k}$ & 0.76 & $(0.35,1.64)$ & 0.48 \\
\hline & Over $\$ 150 k$ & 0.72 & $(0.31,1.66)$ & 0.45 \\
\hline \multirow[t]{4}{*}{ Region } & (Referent: Midwest) & & & \\
\hline & Northeast & 1.05 & $(0.68,1.63)$ & 0.83 \\
\hline & South & 1.27 & $(0.86,1.89)$ & 0.23 \\
\hline & West & 0.62 & $(0.41,0.94)$ & 0.02 \\
\hline \multirow[t]{2}{*}{ Work status } & (Referent: Not working) & & & \\
\hline & Working & 1.35 & $(0.94,1.93)$ & 0.10 \\
\hline Perceived efficacy & (Referent: Very effective) & & & \\
\hline \multirow{2}{*}{$\begin{array}{l}\text { How effective do you think } \\
\text { the influenza vaccine is in }\end{array}$} & Somewhat effective & 1.86 & $(1.07,3.24)$ & 0.03 \\
\hline & It varies from season to season & 4.05 & $(2.21,7.44)$ & $<0.001$ \\
\hline
\end{tabular}




\begin{tabular}{|c|c|c|c|c|}
\hline \multirow{2}{*}{$\begin{array}{l}\text { protecting people from } \\
\text { becoming sick with } \\
\text { influenza? }\end{array}$} & Not effective & 10.36 & $(4.58,23.46)$ & $<0.001$ \\
\hline & Don't know & 9.01 & $(4.63,17.54)$ & $<0.001$ \\
\hline Health insurance & (Referent: Yes) & & & \\
\hline $\begin{array}{l}\text { Do you have health } \\
\text { insurance? }\end{array}$ & No & 2.04 & $(1.09,3.83)$ & 0.03 \\
\hline Barriers & (Referent: No) & & & \\
\hline \multirow{6}{*}{$\begin{array}{l}\text { What are the reasons you } \\
\text { would not get an influenza } \\
\text { vaccine? }\end{array}$} & 1. The vaccine costs too much & 0.34 & $(0.21,0.56)$ & $<0.001$ \\
\hline & $\begin{array}{l}\text { 2. The vaccine is not very effective in } \\
\text { preventing influenza }\end{array}$ & 0.41 & $(0.29,0.58)$ & $<0.001$ \\
\hline & 3. I am not likely to get influenza & 1.95 & $(1.35,2.81)$ & $<0.001$ \\
\hline & $\begin{array}{l}\text { 5. The side effects of the vaccine are } \\
\text { too risky }\end{array}$ & 1.98 & $(1.33,2.94)$ & $<0.001$ \\
\hline & 7. I do not like shots & 1.48 & $(1.01,2.16)$ & 0.04 \\
\hline & 8. I just don't get around to doing it & 0.52 & $(0.38,0.70)$ & $<0.001$ \\
\hline
\end{tabular}

5

6

7

8

9 